\title{
Polymetastatic highly aggressive Small Cell Undifferentiated Neuroendocrine Carcinoma of Ascending Colon
}

Carcinoma neuroendocrino indiferenciado polimetástatico altamente agresivo de célulaș pequeñas de colon ascendente

Orestis loannidis ${ }^{1}$, Charis Chatzidelios ${ }^{1}$, Ioannis Mantzoros ${ }^{1}$, Dimitrios Tatsis ${ }^{1}$, Loukiani Kitsikosta ${ }^{1}$, Christos Chatzakis ${ }^{1}$, Apostolos Makrantonakis ${ }^{1}$, George Paraskevas ${ }^{2}$, Efstathios Kotidis ${ }^{1}$, Manousos G. Pramateftakis ${ }^{1}$ and Konstantinos Tsalis ${ }^{1}$

${ }^{1}$ Fourth Surgical Department; ${ }^{2}$ Department of Anatomy. Medical School, Aristotle University of Thessaloniki, Thessaloniki, Greece

\begin{abstract}
\end{abstract}
Neuroendocrine carcinoma (NEC) of the colon is a rare and very aggressive tumor with poor prognosis. The current case report presents a 53-year-old male with a $6 \mathrm{~cm} \times 10 \mathrm{~cm}$ ascending colon carcinoma, causing large intestine obstruction; with simultaneous multiple hepatic metastases and peritoneal carcinomatosis. Surgical resection of the primary tumor was perrformed, because of the bowel obstruction, to ameliorate the symptoms before the onset of chemotherapy. Histopathology revealed that the tumor was a small-cell undifferentiated NEC. During the postOoperative period, the patient presented pulmonary metastases, and on the 36th post-operative day, death occurred due to respiratory failure.

KEY WORDS: Neuroendocrine tumor. Chromogranin. Neuron specific enolase. Colectomy.

\section{Resumen}

El carcinoma neuroendocrino del colon es un tumor raro y muy agresivo, con mal pronóstico. Se presenta el caso de un hombre de 53 años con un carcinoma de colon ascendente de $6 \times 10 \mathrm{~cm}$ que causa obstrucción del intestino grueso, ocon metástasis hepáticas múltiples simultáneas y carcinomatosis peritoneal. Se realizó la resección quirúrgica del tumor primario, debido a la obstrucción intestinal, para mejorar los síntomas antes del inicio de la quimioterapia. La histopatología revelóque el tumor era un carcinoma neuroendocrino indiferenciado de células pequeñas. Durante el posoperatorio, el paciente presentó metástasis pulmonares y el día 36 posoperatorio se produjo la muerte por insuficiencia respiratoria.

PALABRAS CLAVE: Tumor neuroendocrino. Cromogranina. Enolasa específica de neuronas. Colectomía.

\section{Introduction}

Colonic neuroendocrine carcinomas are characterized by their extreme aggressiveness and poor differentiation, which result to early dissemination and rapid clinical deterioration, even if the primary tumor is minor ${ }^{1-3}$. The rarity of these tumors and the confusion in their classification and nomenclature, have neil allowed their proper evaluation nor the coordination of one common therapeutic strategy ${ }^{4-6}$. In the current case report, we present a 53-year-old man, with a neuroendocrine tumor in the ascending colon with simultaneous hepatic metastasis and peritoneal carcinomatosis who presented pulmonary metastasis during the early postoperative period. 


\section{Case Report}

A 53-year-old man was admitted to our hospital, complaining for weakness, sickliness, weight loss (15 kg in 3 months), right abdominal pain and change in bowel habits, with constipation and obstructive symptoms. On admission, the patient presented malnutrition, was pale and had icteric tinged conjunctiva and skin. His medical history consisted of mild diabetes mellitus, a right adrenal adenoma of $4 \mathrm{~cm}$ which was known for 6 years, heavy smoking and his surgical history consisted of laparoscopic cholecystectomy 5 years ago and bilateral inguinal hernia repair. Physical examination revealed only minor sensitivity mostly on the right abdomen. Laboratory tests showed anemia (Hct 32\%), increased erythrocyte sedimentation rate (48), hyperglycemia (glucose $258 \mathrm{mg} / \mathrm{dl}$ ), jaundice (total bilirubin 6,2 $\mathrm{md} / \mathrm{dl}$ ), and increased gamma-GT (539 U/I). Tumor markers including CEA, CA-19 and AFP, were within the normal range.

The imaging modalities including abdominal and chest X-ray and abdominal CT showed bowel obstruction with the presence of air fluid levels in the small intestine, the existence of mass in right colic flexure of $6 \times 10 \mathrm{~cm}$, two low-density mass in liver left lobe, consistent with metastasis, and other possible metastatic lesions in the liver, swollen paraaortic lymph nodes, and the already known adenoma in right adrenal gland with a diameter of $4.5 \mathrm{~cm}$ (Figure 1). An abdominal MRI was performed which confirmed the diagnosis of multiple hepatic metastasis (Figure 2). Lower gastrointestinal endoscopy confirmed the presence of the cancer at the right colonic flexure.

Due to the obstructive nature of the disease, it was decided to perform an exploratory laparotomy in order to relieve the symptoms, which revealed a carcinoma in the ascending colon of approximately $6 \times 10 \mathrm{~cm}$. The tumor was arising just before the right colic flexure, causing nearly complete intestinal obstruction, thus invading surrounding tissues and adhering to liver right lobe. Moreover, there were intraperitoneal implantations of the tumor and lymph node metastases in the mesentery. In addition, there were many metastatic liver lesions. Proximally to the obstruction, small and large bowel were severely distended. Frozen biopsy of intraperitoneal lesions confirmed the presence of undifferentiated anaplastic carcinoma. The tumor was surgically resected by performing right hemicolectomy with ileo-transverse stapled side to side anastomosis (Figure 3).

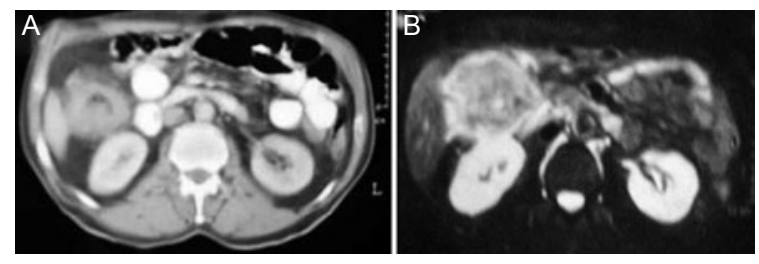

Figure 1: Abdominal CT $(\boldsymbol{A})$ and $M R I(B)$ demonstrating a colonic mass of the right colic flexure

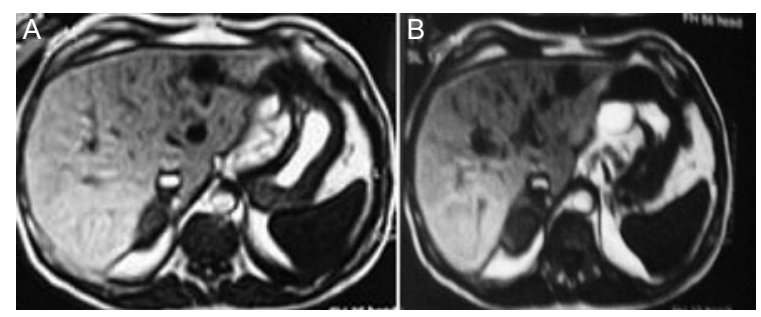

Figure 2: Abdominal MRI showing 2 metastatic lesions of the left tobe (A) and metastatic lesions in both lobes (B).

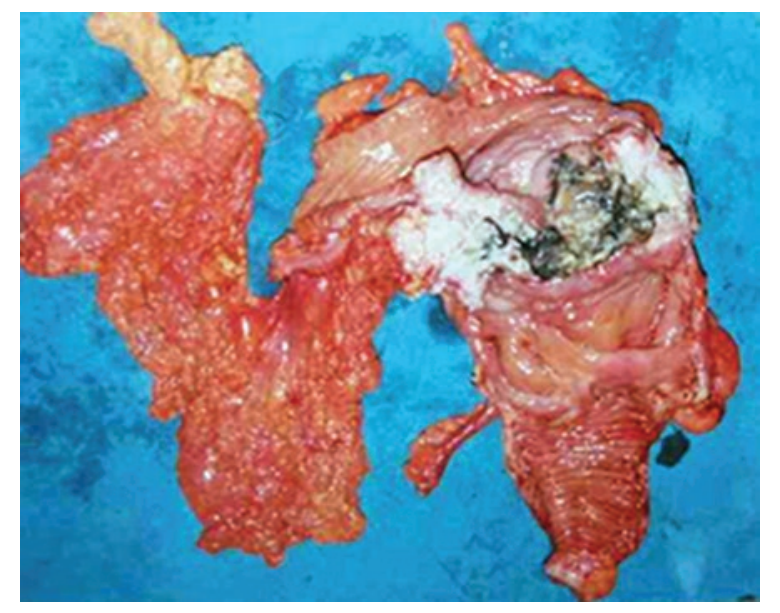

Figure 3: Surgical specimen of the colonic neuroendocrine carcinoma.

Histologically the neoplasm $(10 \times 6 \mathrm{~cm})$ presented ulceration and invaded the entire intestinal wall and extended to the serosa. The tumor had morphotogic features consistent with small cell undifferentiated neuroendocrine carcinoma, infiltrating blood and lymphatic vessels and nerves. Seventeen lymph nodes from the pericolic fat were all positive for presence of metastasis. The immunohistochemical stains showed that tumor cells were positive for the neuronal spe ific enolase (NES), chromogranin-A and keratin.

Following surgery the patient was planned to receive chemotherapy. However, his medical conditition postoperatively deteriorated as the jaundice did not subside, the blood sugar gradually deregulated and respiratory function deteriorated. On the $15^{\text {th }}$ postöperative day, chest X-ray and thoracic CT showed multiple bilateral lung lymphatic infiltrations, causing 
interlobular thickening and ground glass opacity, metastatic nodule in left upper lung lobe and bilateral pleural effusions (figure 4). The possibility of pulmonary embolism was ruled out by lung CT angiography and due to the imaging properties of the lung infiltrations, as they were round shaped whereas pulmonary emboli are triangle shaped. Despite supportive treatment, his medical condition deteriorated further, with affected clinical and laboratory profile, and increased transaminases, bilirubin, ALP, gamma-GT. Respiratory function deteriorated, due to intensification of pleural effusions and lymphatic infiltrations. Moreover, an atrial fibrillation burdened the patient's condition further. On the 36 postoperative day, the patient died of respiratory failure due to irreversible respiratory acidosis. His medical condition prevented the onset of chemotherapy at any stage of the disease. The patient had consented in the publication of the case report.

\section{Discussion}

Neuroendocrine carcinoma (NEC) of the colon, is defined as a malignant epithelial tumor with predominant neuroendocrine differentiation ${ }^{4,7,8}$. The first reference in English literature was in 1978 by Gould and Chefjec $^{8-10}$. Several terms were used such as atypical, pleomorphic, primitive, small-cell carcinoma and carcinoid ${ }^{11}$. It represents between $0.3 \%$ and $3.9 \%$ of the malignancies of the colon $[8,11]$, and constitute the $10-34 \%$ of undifferentiated tumors in this area ${ }^{11}$. It affects a wide age range (26-89 years) [8,12], but mainly 60-70-year-old people [7]. In the present case the onset of the disease was quite early. NECs mostly occur in the rectum, the caecum or the sigmoid colon ${ }^{7,8,12}$. At the time of diagnosis, the tumor usually has a diameter $>5 \mathrm{~cm}$ [13] and the disease is locally and systematically advanced [2,14]. Specifically, in $90 \%$ of cases, the stage of disease is Dukes' C \& D ${ }^{11}$, while in $87 \%$ there is a presence of metastases already ${ }^{8,15}$, as in the current case.

The clinical presentation, except the symptomatology and clinical sings of colon cancer, may include diarrhea, due to intestinal peptides secretion or hypercortisolemia symptoms, due to ACTH production [16]. Metastatic lesions in the liver, lungs, or skin [12] are common. Interestingly, in the current case the patient presented at the time of diagnosis with liver metastases and peritoneal carcinomatosis, but the lung metastasis presented radiologically on the $15^{\text {th }}$ postoperative day.

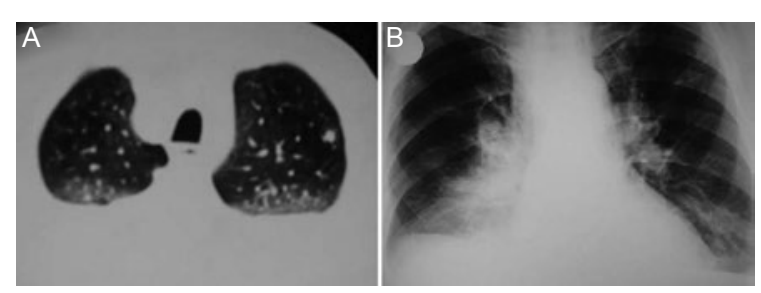

Figure 4: A: Thoracic CT showing multiple bilateral lung lymphatic infiltrations on the posterior segments of the upper lung lobes, depicted as interlobular thickening and ground glass opacity and metastatic nodule in left upper lung lobe. B: Chest X-ray showing bilateral pleural effusions.

Most researchers agree on the theory of origin of these tumor cells from pluripotent stem cells, and therefore separate their origin from carcinoid tumors, which are believed to originate from more advanced in devefopment and more differentiated cells ${ }^{17}$. Also, NECs may occur from syndromes such as MEN1 or MEN2. In this situation, it is important to search family history to determine if any familial syndrome is responsible for the carcinoma. Moreover, the diagnosis can be confirmed with genetic testing ${ }^{16}$. Histologically, the cells of these tumors are small (100-250nm), polymorphic presenting müultiform neurosecretory granules in their cytoplasm ${ }^{8}{ }^{11} .9 \mathrm{~m}$ munohistochemistry is usually positive for neuron specific enolase, keratin and chromogranin A [10,17-19]. The histopathology and immunohistochemistry in the present case was typical of small cell undifferentiated neuroendocrine carcinoma. However, the expression of these immunohistochemical markers is not related to the grade of tumor differentiation.

The treatment is mostly palliative, since these diseases are always advanced ${ }^{16}$. The combination of surgical resection and intensive systemic chemotherapy, offers the best chance for prolonging survival ${ }^{13,15,18}$. Preoperative chemotherapy, is believed to reduce the extent of the disease, and increases the therapeutic surgical ablation capabilities ${ }^{16}$. However, in the current case we firstly performed the colectomy due to the obstructive nature of the disease and planned for chemotherapy later but due to the patient's condition the induction of chemotherapy was prevented at any stage of the disease. Various chemotherapy regimens have been proposed, bufwithout unanimous acceptance ${ }^{16}$. The prevalent pattern is considered to be the one that is used in small-cell fung carcinoma $^{11}$, which combines cisplatin, etoposide and accordingly 5-FU and irinotecan 3,5,16,18,19. Many authors, based on the affinity of these tumors with carcinoids, propose the use of interferon-a, which stimulatesothe activity of Natural Killer cells, and reduces the possible hormonal secretion of these tumors ${ }^{16,18}$. Similar hormone-static action has the synthetic somatostatin analog 
octreotide, but usually these tumors are undifferentiated and do not have hormone-producing activity ${ }^{15,16,18}$. Chemotherapy achieves short term results in less than $10 \%$ of patients ${ }^{16}$. Moreover, if the carcinoma is non-resectable and hormone producible, embolization of hepatic artery may be helpful. The ischemia caused to the tumor cells can reduce their hormone output thus increase sensitivity to chemotherapy regimens. The response to this treatment comprises between $40-80 \%{ }^{16}$. The prognosis is generally poor, because of the great aggressiveness of these tumors ${ }^{15,17}$. The average survival is $6-12$ months ${ }^{10,15}$, while only $12 \%$ of patients survive beyond one year ${ }^{11}$.

\section{Conclusion}

The confusion in the nomenclature of the disease and its rarity, result in its possible under-diagnosis and therefore addressing patients with less aggressiveness than it is required ${ }^{20}$. The use of immunohistochemistry and electron microscopy, can contribute to accurate diagnosis, in order not to confuse these tumors with carcinoid or other undifferentiated adenocarcinomas ${ }^{20}$. Particularly important is the fact that there is a percentage of colonic adenocarcinomas which have a small percentage of neuroendocrine characteristics that are believed to negative affect the prognosis ${ }^{4,9,12}$. More research is required to determine both the diagnostic criteria, and the treatment regimens, since the current methods have disappointing results ${ }^{11,18,21}$.

\section{Ethical disclosures}

Protection of human and animal subjects. The authors declare that the procedures followed were in accordance with the regulations of the relevant clinical research ethics committee and with those of the Code of Ethics of the World Medical Association (Declaration of Helsinki).

Confidentiality of data. The authors declare that they have followed the protocols of their work center on the publication of patient data.

Right to privacy and informed consent. The authors have obtained the written informed consent of the patients or subjects mentioned in the article. The corresponding author is in possession of this document.

\section{References}

1. Jones K, Subramaniam RM, Durnick DK, Peller PJ. F-18-FDG-PET/CT imaging of small cell carcinoma of the colon. Clin Nucl Med 2008;33:645-6. doi: 10.1097/RLU.0b013e31818130c5.

2. Kim HC, Park SI, Park SJ, et al. Small cell carcinoma of the colon: barium study and CT findings. Br J Radiol 2005;78:255-6.

3. Park JS, Kim L, Kim CH, et al. Synchronous large-cell neuroendocrine carcinoma and adenocarcinoma of the colon. Gut Liver 2010:4:122-5. doi: $10.5009 / \mathrm{gnl} .2010 .4 .1 .122$.

4. Shafqat H, Ali S, Salhab M, Olszewski AJ. Survival of patients with neuroendocrine carcinoma of the colon and rectum: a population-based analysis. Dis Colon Rectum 2015;58:294-303. doi: 10.1097/ DCR.0000000000000298.

5. Miyamoto $H$, Kurita N, Nishioka M, et al. Poorly differentiated heuroendocrine cell carcinoma of the rectum: report of a case and literal review. $\mathrm{J}$ Med Invest 2006;53:317-20.

6. Shia J, Tang LH, Weiser MR, et al. Is nonsmall cell type high-grade neuroendocrine carcinoma of the tubular gastrointestinal tract a diștinct disease entity? Am J Surg Pathol 2008;32:719-31. doi: 10.1097IPAS. Ob013e318159371c.

7. Yaziji H, Broghamer WL Jr. Primary small cell undifferentiated carcíloma of the rectum associated with ulcerative colitis. South Med J 1996;89:921-4.

8. Grabowski P, Schönfelder J, Ahnert-Hilger G, et al. Expression of neuroendocrine markers: a signature of human undifferentiated carcinoma of the colon and rectum. Virchows Arch 2002;441:256-63.

9. Grabowski P, Schönfelder J, Ahnert-Hilger G, et al. Heterogeneoüs expression of neuroendocrine marker proteins in human undifferentiated carcinoma of the colon and rectum. Ann N Y Acad Sci 2004;1014:270-4.

10. Kato T, Terashima T, Tomida S, et al. Cytokeratin 20-positive large cell neuroendocrine carcinoma of the colon. Pathol Int 2005;55:524-9.

11. Onoda N, Kobayashi H, Satake K, et al. Neuroendocrine carcinoma of the sigmoid colon: report of a case. Surg Today 1999;29:1079-82.

12. Gaffey MJ, Mills SE, Lack EE. Neuroendocrine carcinoma of the-colon and rectum. A clinicopathologic, ultrastructural, and immunohistochemical study of 24 cases. Am J Surg Pathol 1990;14:1010-23.

13. Yasui $O$, Tsukamoto F, Kudo K. Small cell undifferentiated carcinoma of the ascending colon with rapid enlargement after resection: repoft of a case and review of the literature. Tohoku J Exp Med 2006;209:361-7.

14. Matsuda A, Sasajima K, Matsutani T, et al. Aggressive undifferentiated colon carcinoma producing granulocyte-colony stimulating factor: report of a case. Surg Today 2009;39:990-3. doi: 10.1007/s00595-008-3941-1.

15. Power DG, Asmis TR, Tang LH, Brown K, Kemeny NE. High-grade neuroendocrine carcinoma of the colon, long-term survival in advanced disease. Med Oncol 2011;28 Suppl 1:S169-74. doi: 10.1007/s12032-0109674-1.

16. Ramage JK, Davies AH, Ardill J, et al. Guidelines for the management of gastroenteropancreatic neuroendocrine (including carcinoid) tumours. Gut. 2005;54 Suppl 4:iv1-16.

17. Pascarella MR, McCloskey D, Jenab-Wolcott J, Vala M, Rovito M, McHugh J. Large cell neuroendocrine carcinoma of the colon: A rare and aggressive tumor. J Gastrointest Oncol 2011;2:250-3. doi: 10.3978/j. issn.2078-6891.2011.026.

18. Oberg K. Neuroendocrine tumors of the gastrointestinal tract: recent advances in molecular genetics, diagnosis, and treatment. Curopin Oncol 2005;17:386-91.

19. Rifu K, Koinuma K, Horie $\mathrm{H}$, et al. Sigmoid colon carcinoma with focal neuroendocrine differentiation associated with ulcerative colitis: A case report. Int J Surg Case Rep 2016;23:151-6. doi: 10.1016/j.ijscr.2016.04.035.

20. Reyes CV, Siddiqui MT. Anaplastic carcinoma of the colon: clinicopathologic study of eight cases of a poorly recognized lesion. Ann Diagn, Pathol 1997:1:19-25.

21. Mantzoros I, Savvala N, loannidis O, et al. Midgut neuroendocrinettumor presenting with acute intestinal ischemia. World J Gastroenterol 2017;23:8090-6. doi: 10.3748/wjg.v23.i45.8090. 